\title{
Risk factors for the development of essential hypertension in a Mongolian population of China: a case-control study
}

 \\ ${ }^{1}$ Department of Cardiovascular Medicine, \\ The Second Hospital of Jilin University, Changchun, Jilin, China \\ ${ }^{2}$ Clinical Medical Research Center of the Affiliated Hospital, \\ Inner Mongolia Medical University, Hohhot, Inner Mongolia, China \\ ${ }^{3}$ Department of Medical Administration, \\ Inner Mongolia International Mongolian Hospital, \\ Hohhot, Inner Mongolia, China \\ Corresponding authors: S. Li / X. Su \\ E-mail: xlsu2012@gmail.com / nsd11971@sina.com
}

Genet. Mol. Res. 13 (2): 3283-3291 (2014)

Received February 6, 2013

Accepted July 19, 2013

Published April 29, 2014

DOI http://dx.doi.org/10.4238/2014.April.29.6

\begin{abstract}
Lifestyle, habits, diet, and genetics are all important factors associated with the prevalence of hypertension. Many association studies have been performed in the Chinese Han population, whereas data explaining the high prevalence of hypertension in the Mongolian population remain scarce. In the present study, we aimed to determine the factors associated with the development of essential hypertension in Mongolians. A total of 194 hypertensive cases and 201 controls from Dongwu County were enrolled in the study. Demographics, anthropometric and blood biochemical parameters, food intake, lifestyle, habits, education, occupation, and family history were recorded for each subject. Genotype and allele frequencies of six single nucleotide polymorphisms (SNPs) of the kallikrein 1 (KLK1) gene were also examined. Mean body
\end{abstract}


mass index, waistline, hipline, blood sugar, blood urea nitrogen, creatinine, uric acid, total cholesterol, triglyceride, and low-density lipoprotein levels were all significantly higher in the hypertensive group $(\mathrm{P}<0.01)$. Hypertensives consumed less milk, vegetables, and fruits, and had higher cigarette, alcohol, and salt intake $(\mathrm{P}<0.05)$. There were also less regular physical exercisers and manual workers among the hypertensive group $(\mathrm{P}<0.05)$. The mean inheritance rank of the hypertensive group was higher than that of controls ( $\mathrm{P}$ $<0.05)$. There were no differences in the distribution of genotype and allele frequencies of the six SNPs between the hypertensive and control groups $(\mathrm{P}>0.05)$. These results suggest that dietary history and habits have the most important influence on the development of essential hypertension in the Mongolian population.

Key words: Diet; Essential hypertension; Habits; Lifestyle; Mongolians

\section{INTRODUCTION}

The primary causes of essential hypertension include heredity, environment, habits, and dietary history (Carretero and Oparil, 2000; Dickinson et al., 2006). All of these factors interactively contribute to the development of hypertension. Although some hypertension-related factors have been generally accepted by researchers (Carretero and Oparil, 2000), others remain controversial (Dickinson et al., 2006; Vaidya and Forman, 2010; Mesas et al., 2011). Due to genetic instability across and within populations, particularly because of the introduction of foreign genes, the isolation of the genetic component related to the development of essential hypertension is challenging (Lifton et al., 2001; International Consortium for Blood Pressure Genome-Wide Association Studies et al., 2011). Mongolians, the ninth most common minority nationality population of China, generally live in relatively isolated communities, and some follow old nomadic traditions. Because Mongolians rarely marry members of other nationalities, they are good candidates for genetic studies.

According to the latest report of the PRC National Blood Pressure Survey Cooperative Group of China (1995), the prevalence of hypertension in the Mongolian population $(20.2 \%)$ is significantly higher than that in the Han population $(13.7 \%)$ and the total prevalence in China (13.6\%). Habits, lifestyle, and heredity are all important factors associated with the prevalence of hypertension in different nationalities (PRC National Blood Pressure Survey Cooperative Group, 1995). Many association studies have been conducted in the Han population to identify risk factors for hypertension in recent years (Li et al., 2006; Chen et al., 2009, 2010). However, data available explaining the high prevalence of hypertension in Mongolians remain scarce (Li et al., 2008; Zhao et al., 2008; Tian et al., 2009).

From December 2011 to September 2012, a case-control study was organized by the Affiliated Hospital of Inner Mongolia Medical University, with the cooperation of the Inner Mongolia International Mongolian Traditional Medicine Hospital and the Second Affiliated Hospital of Jilin University, which aimed to determine the factors associated with the development of essential hypertension in Mongolians, and to collect timely and sufficient information to support future hypertension prevention programs in the Mongolian population. 


\section{MATERIAL AND METHODS}

\section{Study population}

Study subjects were enrolled from Dongwu County, Xilin Gol League, Inner Mongolia Autonomous Region, China. Hypertensive subjects were enrolled if they met the following criteria: a) of Mongolian descent; b) aged between 35 and 65 years; c) a permanent resident of the local area; d) systolic blood pressure (SBP) $\geq 140 \mathrm{mmHg}$ and/or diastolic blood pressure (DBP) $\geq 90 \mathrm{mmHg}$; e) had not taken any antihypertensive medications within 1 month before the study; f) no secondary hypertension and not presently pregnant; and g) willing to participate in the present study. The controls also needed to meet the criteria a, b, c, f, and g above, and their SBP and DBP needed to be lower than 140 and 90 $\mathrm{mmHg}$, respectively.

\section{Study design}

Eligible subjects (including controls) were invited for a face-to-face interview, and a socio-demographic characteristic-based questionnaire was designed to collect information on lifestyle, habits, and dietary history. Written informed consent was obtained by signature or thumbprint. After the interview, all subjects underwent a blood pressure check in local hospitals, and venous blood samples were collected for blood biochemical examination and human tissue kallikrein 1 (KLK1) gene polymorphism analysis. All examinations were provided at no cost to the participant, and all studies were approved by the Ethics Committee of the Affiliated Hospital of Inner Mongolia Medical University.

\section{Measurement of blood pressure and anthropometrics}

Blood pressure was measured by well-trained nurses using a mercury-gravity manometer with appropriate sized cuffs after the subjects were kept silent in a seated pose for $30 \mathrm{~min}$ (Jiang et al., 2011). Triplicate measurements were carried out on the left arm with a 1-min interval between each reading. We defined SBP and DBP as Korotkoff phase I and V, respectively (Jiang et al., 2011). The mean of the three blood measurements was used in statistical analysis.

Height, waistline, hipline, and weight measures were also taken and used to evaluate the somatotype of subjects. Triplicate measurements were carried out by three different interviewers, and the mean value was used in statistical analysis.

\section{Blood biochemical examination}

Blood samples were collected after an overnight fast, and blood sugar, blood urea nitrogen (BUN), creatinine (CRE), uric acid (UA), total cholesterol (TC), triglyceride (TG), high-density lipoprotein (HDL), and low-density lipoprotein (LDL) levels were measured within $8 \mathrm{~h}$ in a local hospital (Beckman Coulter Unicel DxC 800 Synchron Clinical Systems; Beckman Coulter Company, Fullerton, CA, USA). 


\section{DNA extraction and KLK1 gene polymorphism analysis}

Genomic DNA was extracted from peripheral blood leukocytes using a commercial blood DNA extraction kit (Genomic DNA purification kit; TaKaRa Biotechnology, Dalian, China), and stored at $-20^{\circ} \mathrm{C}$. The six tag single nucleotide polymorphisms (SNPs) of the KLK1 gene were genotyped using the polymerase chain reaction (PCR)/ligase detection reaction assay (Xiao et al., 2006). Primers were synthesized by Shanghai Sangon Biological Engineering Technology \& Services. Each set of ligase detection reaction probes comprised one common probe and two discriminating probes.

The target DNA sequences were amplified using a multiplex PCR method. PCRs for each subject were carried out in a final volume of $20 \mu \mathrm{L}$ containing 1 X PCR buffer, $3.0 \mathrm{mM} \mathrm{MgCl}, 2.0 \mathrm{mM}$ deoxynucleotide triphosphates, $0.2 \mathrm{pM}$ primers, $0.3 \mu \mathrm{L}$ Qiagen HotStarTaq Polymerase (QIAGEN, Shenzhen, China), $4 \mu \mathrm{L}$ 1X Q-solution, and 10-20 ng genomic DNA. Thermal cycling was performed in the Gene Amp PCR system 9600 (PerkinElmer, Waltham, MA, USA) with an initial denaturation of $2 \mathrm{~min}$ at $95^{\circ} \mathrm{C}$, followed by 35 cycles of denaturation at $94^{\circ} \mathrm{C}$ for $30 \mathrm{~s}$, annealing at $54^{\circ} \mathrm{C}$ for 1.5 min, and extension at $72^{\circ} \mathrm{C}$ for $1 \mathrm{~min}$, followed by a final extension at $72^{\circ} \mathrm{C}$ for $10 \mathrm{~min}$.

The ligation reaction for each subject was carried out in a final volume of $10 \mu \mathrm{L}$ containing 1 X NEB Taq DNA ligase buffer, $0.05 \mathrm{pM}$ of each probe mix, $0.05 \mu \mathrm{L}$ Taq DNA ligase (NEB Biotechnology, Beijing, China), and $1 \mu \mathrm{L}$ multi-PCR product. The ligase detection reaction was performed at $95^{\circ} \mathrm{C}$ for $2 \mathrm{~min}$, followed by 30 cycles of $94^{\circ} \mathrm{C}$ for $30 \mathrm{~s}$, and $50^{\circ} \mathrm{C}$ for 25 $\mathrm{s}$. The fluorescent products of the ligase detection reaction were differentiated by $5 \%$ polyacrylamide gel electrophoresis, and data were collected using the GENESCANTM627 software.

\section{Statistical analysis}

The Student $t$-test was used to evaluate the body mass index (BMI), waistline, hipline, and blood biochemical data between hypertension patients and controls. The intake levels of each kind of food were calculated based on the descriptions provided during the interview. The intake levels were divided into certain ranks (details are shown in Results) according to the mean consumption of the local area. Generally, the status based on the last 10 years of dietary history was taken into account. The rank sum test was used to evaluate food intake differences between hypertensives and controls, and was used to assess cigarette and alcohol intake, as well as education differences between the two groups.

Hardy-Weinberg equilibrium (HWE) of KLK1 genotype distributions in hypertensives and controls was tested with the HWE program (Hua et al., 2005). The chi-squared test was used to compare the allele and genotype frequencies between hypertensives and controls. The chi-squared test was also used to compare the proportion of the population consuming high salt diets and that were physical exercisers and mental laborers/manual workers between the two groups.

All data were analyzed with the SPSS version 16 software. Statistical significance was accepted at $\mathrm{P} \leq 0.05$. All $\mathrm{P}$ values were two-sided.

\section{RESULTS}

\section{Study population}

A total of 194 hypertensives and 201 controls were enrolled in the study. The mean 
age of the hypertensive and control groups was $47.51 \pm 10.31$ and $48.13 \pm 9.85$ years, respectively, and the ratio of males to females was 93 to 101 and 92 to 109, respectively. There was no statistically significant difference in age $(\mathrm{P}=0.937)$ or gender ratio $(\mathrm{P}=0.913)$ between the two groups (Table 1). The mean SBP and DBP of hypertensives were 165.4 \pm 27.1 and 102.2 \pm $16.1 \mathrm{mmHg}$, respectively, which was significantly higher than those of controls $(120.4 \pm 11.8$ $\mathrm{mmHg}$ for SBP and $78.6 \pm 7.3 \mathrm{mmHg}$ for DBP, $\mathrm{P}<0.001$; Table 1).

Almost all participants were willing to undergo all aspects of the study, except for 4 hypertensive individuals and 8 control subjects who refused to provide venous blood samples, and 34 hypertensive and 21 control subjects refused to participate in the polymorphism analysis of the KLK1 gene for uncertain reasons.

The mean BMI, waistline, and hipline of the hypertensive group were all significantly higher than those of the control group ( $\mathrm{P}<0.001$ for all, Table 1). In fact, we found that the "pear"-shaped body was more commonly observed in the hypertensive group during the face-to-face interview.

The mean concentrations of blood sugar, BUN, CRE, UA, TC, TG, and LDL in venous blood samples were all significantly higher in the hypertensive group compared to controls ( $\mathrm{P}<0.01$ for blood sugar and $\mathrm{BUN}$; $\mathrm{P}<0.001$ for CRE, UA, TC, TG, and LDL; Table 2). However, there was no difference in HDL between the two groups.

Table 1. Demographic, blood pressure and anthropometric parameters.

\begin{tabular}{lccr}
\hline Variables & Hypertensives $(\mathrm{N}=194)$ & Controls $(\mathrm{N}=201)$ & $\mathrm{P}$ \\
\hline Age $($ years $)$ & $47.51 \pm 10.31$ & $48.13 \pm 9.85$ & 0.937 \\
Gender $(\mathrm{M} / \mathrm{F})$ & $93 / 101$ & $92 / 109$ & 0.913 \\
SBP $(\mathrm{mmHg})$ & $165.4 \pm 27.1$ & $120.4 \pm 11.8$ & $<0.001$ \\
DBP $(\mathrm{mmHg})$ & $102.2 \pm 16.1$ & $78.6 \pm 7.3$ & $<0.001$ \\
BMI $\left(\mathrm{cm} / \mathrm{kg}^{2}\right)$ & $29.1 \pm 5.1$ & $24.6 \pm 3.8$ & $<0.001$ \\
Waistline $(\mathrm{cm})$ & $95.2 \pm 15.1$ & $83.0 \pm 11.5$ & $<0.001$ \\
Hipline $(\mathrm{cm})$ & $106.5 \pm 9.7$ & $98.0 \pm 9.9$ & $<0.001$ \\
\hline
\end{tabular}

Data are reported as means \pm standard deviation. $\mathrm{SBP}=$ systolic blood pressure; $\mathrm{DBP}=$ diastolic blood pressure; $\mathrm{BMI}=$ body mass index.

\begin{tabular}{|c|c|c|c|}
\hline Variables & Hypertensives $(\mathrm{N}=190)$ & Controls $(\mathrm{N}=193)$ & $\mathrm{P}$ \\
\hline Blood sugar (mM) & $5.7 \pm 1.7$ & $5.2 \pm 1.2$ & $<0.01$ \\
\hline BUN (mM) & $5.3 \pm 1.7$ & $4.8 \pm 1.2$ & $<0.01$ \\
\hline CRE $(\mu \mathrm{M})$ & $82.0 \pm 16.9$ & $74.9 \pm 13.6$ & $<0.001$ \\
\hline $\mathrm{UA}(\mu \mathrm{M})$ & $237.7 \pm 78.0$ & $200.3 \pm 66.3$ & $<0.001$ \\
\hline $\mathrm{TC}(\mathrm{mM})$ & $4.5 \pm 0.9$ & $4.1 \pm 1.0$ & $<0.001$ \\
\hline $\mathrm{TG}(\mathrm{mM})$ & $1.5 \pm 1.1$ & $0.1 \pm 0.6$ & $<0.001$ \\
\hline $\mathrm{HDL}(\mathrm{mM})$ & $1.5 \pm 0.4$ & $1.5 \pm 0.4$ & $>0.05$ \\
\hline $\mathrm{LDL}(\mathrm{mM})$ & $3.5 \pm 1.0$ & $2.9 \pm 1.0$ & $<0.001$ \\
\hline
\end{tabular}

Data are reported as means \pm standard deviation. $\mathrm{BUN}=$ blood urea nitrogen; $\mathrm{CRE}=$ creatinine; $\mathrm{UA}=$ uric acid; $\mathrm{TC}=$ total cholesterol; TG = triglyceride; $\mathrm{HDL}=$ high-density lipoprotein; $\mathrm{LDL}=$ low-density lipoprotein.

\section{Dietary history, lifestyle, habits, education, occupation, and inheritance}

Nearly $7 \%$ of the dietary history data were excluded in the analysis. The main reason was due to the inability of participants to clearly describe their daily dietary intake, or because 
of a great change in diet in the last 10 years due to a sudden disease or other uncertain reasons. The milk, vegetable, and fruit intakes of the hypertensive group were all significantly lower than those in controls $(\mathrm{P}<0.05$ for all; Table 3$)$. However, the intake of eggs, meat, beans, and bean products did not differ between the two groups ( $\mathrm{P}>0.05$ for all; Table 3$)$.

\begin{tabular}{|c|c|c|c|c|c|}
\hline \multirow[t]{2}{*}{ Food intake } & \multicolumn{2}{|c|}{ Hypertensives } & \multicolumn{2}{|c|}{ Controls } & \multirow[t]{2}{*}{$\mathrm{P}$} \\
\hline & No. & Mean rank & No. & Mean rank & \\
\hline Milk & 174 & 168.8 & 185 & 190.6 & $<0.05$ \\
\hline Egg & 174 & 172.3 & 187 & 189.1 & $>0.05$ \\
\hline Bean and bean products & 177 & 183.0 & 185 & 180.0 & $>0.05$ \\
\hline Meat & 182 & 191.9 & 192 & 183.4 & $>0.05$ \\
\hline Vegetable & 183 & 177.1 & 193 & 199.3 & $<0.05$ \\
\hline Fruit & 180 & 175.3 & 192 & 197.0 & $<0.05$ \\
\hline
\end{tabular}

The intakes are divided into 4 ranks. Milk (mL/day): rank 1, less than 100; rank 2, 100-200; rank 3, 201-400; rank 4, 401 or more. Egg (eggs/week): rank 1, less than 2; rank 2, 2-3; rank 3, 4-5; rank 4, 6 or more. Bean and bean products (g/week): rank 1, less than 125; rank 2, 125-250; rank 3, 251-500; rank 4, 501 or more. Meat (g/week): rank 1, less than 500; rank 2, 500-1500; rank 3, 1501-2500; rank 4, 2501 or more. Vegetable (g/week): rank 1, less than 1500; rank 2, 1500-2500; rank 3, 2501-3500; rank 4, 3501 or more. Fruit (g/week): rank 1, less than 500; rank 2, 500-1000; rank 3, 1001-1500; rank 4, 1501 or more.

Smoking, drinking, high salt diet, and physical exercise were also investigated in the study, focusing particularly on the last 10 years. In evaluating high salt diet, we found that salt intake was not limited to the three meals per day, as salty snacks, such as jerked beef and dry pickles, are popular among local residents. Therefore, the salt intake from these snacks was also taken into account besides daily meals. The consumption of salt, cigarette, and alcohol was determined by the interviewer based on statements of study subjects.

After all data were normalized, we found that cigarette and alcohol consumption was significantly higher in hypertensives than in controls $(\mathrm{P}<0.05$ for cigarette consumption and $\mathrm{P}<0.001$ for alcohol consumption; Table 4), and the proportion of subjects with high salt diets was higher in hypertensives than in controls $(\mathrm{P}<0.01$; Table 4$)$. However, the proportion of subjects who participated in regular physical exercise was significantly lower in hypertensives than in controls $(\mathrm{P}<0.01$; Table 4$)$.

No significant difference in education was found between the two groups $(P>0.05$; Table 4). In this study, occupation was divided into mental laborer and manual worker categories. The former mainly included teachers, doctors, policemen, and government officers, and the latter generally consisted of farmers, herders, and industrial workers. We found a higher percentage of mental laborers in the hypertensive group than in the control group $(\mathrm{P}<0.05$; Table 4$)$. In order to eliminate sample bias, the subjects whose mothers or fathers died before the age of 45 years were excluded from the inheritance analysis. For the remaining subjects, the mean inheritance rank of hypertensives was significantly higher than that of controls $(\mathrm{P}<0.05$; Table 4$)$.

\section{KLK1 gene polymorphisms}

We investigated the association of six SNPs (rs2659058, rs2659103, rs2659104, rs 2740502, rs1054713, and rs5517) of the KLK1 gene with hypertension. Genotype frequencies of 
the six SNPs of the KLK1 gene satisfied HWE in subjects $(\mathrm{P}>0.05)$. The genotype distributions and allele frequencies are shown in Table 5. There were no differences in the distribution of genotype and allele frequencies of the six SNPs between hypertensives and controls $(\mathrm{P}>0.05$; Table 5$)$.

\begin{tabular}{|c|c|c|c|c|c|}
\hline \multirow[t]{2}{*}{ Variables } & \multicolumn{2}{|c|}{ Hypertensives } & \multicolumn{2}{|c|}{ Control } & \multirow[t]{2}{*}{$\mathrm{P}$} \\
\hline & No. & Mean rank or ratio & No. & Mean rank or ratio & \\
\hline Cigarette intake & 183 & 198.8 & 194 & 179.8 & $<0.05$ \\
\hline Alcohol intake & 182 & 200.4 & 191 & 174.3 & $<0.001$ \\
\hline High salt diet & 166 & $92 / 74$ & 177 & $75 / 102$ & $<0.01$ \\
\hline Physical exercise & 184 & $116 / 68$ & 193 & $141 / 52$ & $<0.05$ \\
\hline Education & 183 & 182.1 & 198 & 199.2 & $>0.05$ \\
\hline Occupation (ml/mw) & 175 & $78 / 97$ & 191 & $66 / 125$ & $<0.05$ \\
\hline Inheritance & 148 & 175.5 & 176 & 151.5 & $<0.05$ \\
\hline
\end{tabular}

High salt diet was defined as more than $6 \mathrm{~g}$ salt per day. Data are reported as more than $6 \mathrm{~g}$ per day/less than $6 \mathrm{~g}$ per day. Data in physical exercise are reported as do physical exercise at least twice a week/less than twice a week. For occupation, ml: mental laborers; mw: manual workers. The condition of cigarette and alcohol intake, education, and inheritance are divided into 4, 5 and 3 ranks, respectively. Cigarette intake (total cigarette intake in recent 10 years): rank 1, less than 100; rank 2, 100-2000; rank 3, 2001-4000; rank 4, 4001 or more. Alcohol intake (total alcohol intake in recent 10 years, L): rank 1, less than 1, rank 2, 1-10, rank 3, 11-100, rank 4, 101 or more. Education: rank 1, illiteracy; rank 2, primary school; rank 3, middle school; rank 4, high school; rank 5, junior college or higher. Inheritance: rank 1, none; rank 2, maternal or paternal; rank 3, maternal and paternal.

Table 5. Distribution of genotype and allele frequencies of six SNPs of the KLK1 gene.

\begin{tabular}{|c|c|c|c|c|}
\hline Gene & Genotype/allele & Hypertensives N (\%) & Controls N (\%) & $\mathrm{P}$ \\
\hline \multirow[t]{5}{*}{ rs 2659058} & $\mathrm{AA}$ & $93(59.6)$ & $112(65.1)$ & $>0.05$ \\
\hline & $\mathrm{AG}$ & $54(34.6)$ & $52(30.2)$ & \\
\hline & GG & $9(5.8)$ & $8(4.7)$ & \\
\hline & A & $240(76.9)$ & $276(80.2)$ & $>0.05$ \\
\hline & G & $72(23.1)$ & 68 (19.8) & \\
\hline \multirow[t]{5}{*}{ rs2659103 } & $\mathrm{GG}$ & $93(59.6)$ & $112(65.1)$ & $>0.05$ \\
\hline & GT & $55(35.3)$ & $52(30.2)$ & \\
\hline & TT & $8(5.1)$ & $8(4.7)$ & \\
\hline & $\mathrm{G}$ & 241 (77.2) & $276(80.2)$ & $>0.05$ \\
\hline & $\mathrm{T}$ & $71(22.8)$ & $68(19.8)$ & \\
\hline \multirow[t]{5}{*}{ rs2659104 } & AA & $12(7.7)$ & $9(5.2)$ & $>0.05$ \\
\hline & AG & $51(32.7)$ & $53(30.8)$ & \\
\hline & GG & $93(59.6)$ & $110(64.0)$ & \\
\hline & A & $75(24.0)$ & 71 (20.6) & $>0.05$ \\
\hline & G & $237(76.0)$ & $273(79.4)$ & \\
\hline \multirow[t]{5}{*}{ rs 2740502} & $\mathrm{CC}$ & $94(60.3)$ & $101(58.7)$ & $>0.05$ \\
\hline & CG & $54(34.6)$ & $57(33.1)$ & \\
\hline & GG & $8(5.1)$ & $14(8.1)$ & \\
\hline & $\mathrm{C}$ & 242 (77.6) & $259(75.3)$ & $>0.05$ \\
\hline & G & $70(22.4)$ & $85(24.7)$ & \\
\hline \multirow{5}{*}{ rs 1054713} & $\mathrm{CC}$ & $93(59.6)$ & $112(65.1)$ & $>0.05$ \\
\hline & CT & $54(34.6)$ & $52(30.2)$ & \\
\hline & TT & $9(5.8)$ & $8(4.7)$ & \\
\hline & $\mathrm{C}$ & $240(76.9)$ & $276(80.2)$ & $>0.05$ \\
\hline & $\mathrm{T}$ & $72(23.1)$ & $68(19.8)$ & \\
\hline \multirow[t]{5}{*}{ rs 5517} & AA & $33(21.6)$ & $41(24.1)$ & $>0.05$ \\
\hline & $\mathrm{AG}$ & $78(51.0)$ & $73(42.9)$ & \\
\hline & GG & $42(27.4)$ & $56(32.9)$ & \\
\hline & $\mathrm{A}$ & $144(47.1)$ & 155 (45.6) & $>0.05$ \\
\hline & G & $162(52.9)$ & $185(54.4)$ & \\
\hline
\end{tabular}

Thirty-eight hypertensives and 29 controls refused to participate in the polymorphism analysis of the KLK1 gene; therefore, totally 156 hypertensives and 172 controls were enrolled. For sample reason, the polymorphism of rs5517 was observed in 153 hypertensives and 170 controls. 


\section{DISCUSSION}

Dongwu County $\left(116^{\circ} \mathrm{E}, 44^{\circ} \mathrm{N}\right)$ is located in the northeast of Inner Mongolia Autonomous Region, China, neighboring Mongolia. There are approximately 55,000 permanent residents of this area. Nearly $75 \%$ of the residents are Mongolians, and more than $40 \%$ of residents are herders. Because most herders lived far away from the area where our survey was performed, only approximately $20 \%$ of the study subjects who enrolled in this study were herders.

Until recently, there was no epidemiological screening of the prevalence of essential hypertension in this area. However, several similar studies performed in the Mongolian population may provide some useful information. The prevalence of essential hypertension is $37.4 \%$ in Naiman County $\left(120^{\circ} \mathrm{E}, 43^{\circ} \mathrm{N}\right)$ (Li et al., 2008$), 34.5^{\circ}$ in Hulun Buir League $\left(118^{\circ} \mathrm{E}, 49^{\circ} \mathrm{N}\right)$ (Tian et al., 2009), and $40.2 \%$ in Fuxin County $\left(121^{\circ} \mathrm{E}, 42^{\circ} \mathrm{N}\right.$ ) (Zhao et al., 2008). Overall, based on a large-scale nutrition and health survey conducted in China in 2002 (Li et al., 2005), the total prevalence of essential hypertension in Mongolians is $26.7 \%$, which is significantly higher than that in the Han population (22.7\%) and the total Chinese population (18.8\%).

Consistent with previous reports (Carretero and Oparil, 2000; Vaidya and Forman, 2010), obesity, dietary history, habit, occupation, and inheritance were all found to be hypertension-related risk factors in the Mongolian population of China. In our opinion, dietary history is the most important factor. Since the development of obesity depends on dietary history to a great extent, and some habits, such as high salt diets and alcohol consumption, which are both tightly associated with dietary history, to our surprise, meat intake, a commonly accepted hypertensionrelated factor (Carretero and Oparil, 2000), was not associated with the development of hypertension in the Mongolian population assessed in the present study. One possible reason for this conflicting result might be due to the relatively lower fat content of beef and mutton compared to pork, which are more popular in the local Mongolian population. Furthermore, we demonstrated, for the first time, that milk intake, which has been neglected in most of the previous association studies, is also a hypertension-related factor in the Mongolian population.

Although some controversy remains with respect to the relationship between smoking and hypertension, the majority of scientists accept that smoking is indeed one of the risk factors of hypertension, especially when the specific quantity of cigarette intake is incorporated in statistical analyses (Virdis et al., 2010). Results of the present study showed that blood pressure was influenced by cigarette intake.

During the investigation, we found that the biggest lifestyle difference between the Han and Mongolian populations was related to dietary history and habits. Higher meat and salt intake and lower vegetable and fruit intake were commonly observed in the Mongolian population compared to the Han population. In addition, alcohol consumption and smoking are more popular habits among Mongolians. The large majority of study subjects (males: $79.2 \%$, females: $71.1 \%$ ) were regular alcohol drinkers, and more than $60 \%$ of study subjects (males: 69.1\%, females: 39.5\%) were smokers. Our results suggested that the high proportion of smokers and alcohol drinkers, as well as the difference in dietary history, are important contributors to explain the high prevalence of hypertension in the Mongolian population.

In 2007, a large-scale KLK1 gene polymorphism analysis was performed in Peking, China (Zhao et al., 2007), which revealed an association between the rs5517 SNP and essential hypertension in a Peking Han population. However, another report from the Anhui Province of China suggested that rs5516 rather than rs5517 was associated with hypertension (Jiang et 
al., 2011). The conflicting results may be due to sampling artifacts. In the present study, we did not find any relationship between hypertension and genetic variations of the KLK1 gene in the Mongolian population.

In conclusion, our study suggests that dietary history and habits have the most important influence on the development of essential hypertension in the Mongolian population. Quitting smoking and drinking, as well as changes in the diet should be considered as major components of a hypertension prevention program in the Mongolian population.

\section{ACKNOWLEDGMENTS}

(\#2011MS1124).

\section{REFERECES}

Carretero OA and Oparil S (2000). Essential hypertension. Part I: definition and etiology. Circulation 101: 329-335.

Chen A, Chen X, Shi R, Guo Y, et al. (2009). Association of genetic polymorphism in phenylethanolamine-N-methyl transferase with essential hypertension in Changsha Han people. Zhong. Nan. Da Xue Xue Bao Yi Xue Ban. 34: 1120-1125.

Chen M, Chen X, Guo Y, Shi R, et al. (2010). Brain natriuretic peptide rs198388 polymorphism and essential hypertension in Hunan Han people. Zhong. Nan. Da Xue Xue Bao Yi Xue Ban. 35: 1207-1213.

Dickinson HO, Mason JM, Nicolson DJ, Campbell F, et al. (2006). Lifestyle interventions to reduce raised blood pressure: a systematic review of randomized controlled trials. J. Hypertens. 24: 215-233.

Hua H, Zhou S, Liu Y, Wang Z, et al. (2005). Relationship between the regulatory region polymorphism of human tissue kallikrein gene and essential hypertension. J. Hum. Hypertens. 19: 715-721.

International Consortium for Blood Pressure Genome-Wide Association Studies, Ehret GB, Munroe PB, Rice KM, et al. (2011). Genetic variants in novel pathways influence blood pressure and cardiovascular disease risk. Nature 478: 103-109.

Jiang S, Hsu YH, Venners SA, Zhang Y, et al. (2011). Effects of protein coding polymorphisms in the kallikrein 1 gene on baseline blood pressure and antihypertensive response to irbesartan in Chinese hypertensive patients. J. Hum. Hypertens. 25: 327-333.

Li HM, Tong WJ, Liu YB and Li YS (2008). Prevalence and path arialysis of risk factors of hypertension in Mongolian people. Clin. J. Public Health 24: 263-265.

Li QX, Zhu XL, Du RY, Zhang YQ, et al. (2006). Polymorphic Hind III restriction site of the Y chromosome and essential hypertension in Chinese Han People. Zhonghua Yi Xue Za Zhi. 86: 1390-1393.

Li LM, Rao KQ, Kong LZ, Yao CH, et al. (2005). A description on the Chinese national nutrition and health survey in 2002. Zhonghua Liu Xing. Bing. Xue Za Zhi. 26: 478-484.

Lifton RP, Gharavi AG and Geller DS (2001). Molecular mechanisms of human hypertension. Cell 104: 545-556.

Mesas AE, Leon-Munoz LM, Rodriguez-Artalejo F and Lopez-Garcia E (2011). The effect of coffee on blood pressure and cardiovascular disease in hypertensive individuals: a systematic review and meta-analysis. Am. J. Clin. Nutr. 94: 1113-1126.

PRC National Blood Pressure Survey Cooperative Group (1995). Prevalence and development trends of hypertension in China. Chin. J. Hypertens. 3: 7-13.

Tian S, Wang ZX, Lin XM and Su R (2009). The study of hypertension and its related factors among Mongolian residents in Hulunbeier region. Chin. J. Prev. Contr. Chron. Dis. 17: 49-51.

Vaidya A and Forman JP (2010). Vitamin D and hypertension: current evidence and future directions. Hypertension 56: 774-779.

Virdis A, Giannarelli C, Neves MF, Taddei S, et al. (2010). Cigarette smoking and hypertension. Curr. Pharm. Des. 16: 2518-2525.

Xiao Z, Xiao J, Jiang Y, Zhang S, et al. (2006). A novel method based on ligase detection reaction for low abundant YIDD mutants detection in hepatitis B virus. Hepatol. Res. 34: 150-155.

Zhao W, Wang L, Lu X, Yang W, et al. (2007). A coding polymorphism of the kallikrein 1 gene is associated with essential hypertension: a tagging SNP-based association study in a Chinese Han population. J. Hypertens. 25: 1821-1827.

Zhao FF, Ma SM, Zheng LQ and Sun ZQ (2008). Characterization and risk factor analysis of hypertension patients in Mongolian people of Fuxin county, Liaoning province. Chin. J. Pract. Int. Medi. 28: 58-60. 